\title{
DEMOSTHENIS ORATIONES
}

\author{
EDIDIT \\ CAROLVS FVHR \\ EDITIO MAIOR \\ VOLVMEN I PARS I-III \\ ORATIONES I-XIX CONTINENS \\ EDITIO STEREOTYPA \\ EDITIONIS PRIMAE (MCMXIV)
}

\section{需}

STVTGARDIAE ET LIPSIAE

IN AEDIBVS B.G.TEVB̈NERI MCMXCIV 
Die Deutsche Bibliothek - CIP-Einheitsaufnahme

Demosthenes:

[Orationes]

Demosthenis Orationes / ed. Carolus Fuhr. -

Ed. maior, Ed. stereotypa ed. 1. (1914), [Leinenausg.]. -

Stutgardiae; Lipsiae : Teubner.

(Bibliotheca scriptorum Graecorum et Romanorum Teubneriana)

NE: Fuhr, Carolus [Hrsg.]; Demosthenes: [Sammlung]

Ed. maior, Ed. stereotypa ed. 1. (1914), [Leinenausg.]

Vol. 1. Ps. 1/3 (1994)

ISBN 3-8154-1254-4

Das Werk einschließlich aller seiner Teile ist urheberrechtlich geschützt. Jede Verwertung außerhalb der engen Grenzen des Urheberrechtsgesetzes ist ohne Zustimmung des Verlages unzulässig und strafbar. Das gilt besonders für Vervielfältigungen, Übersetzungen,

Mikroverfilmungen und die Einspeicherung und Verarbeitung in elektronischen Systemen.

(C) B. G. Teubner Verlagsgesellechaft Leipzig 1994

Printed in Germany

Druck und Bindung: Druckhaus Köthen $\mathrm{GmbH}$ 